\title{
Fatigue short crack propagation behavior of selective laser melted Inconel 718 alloy by in-situ SEM study: Influence of orientation and temperature
}

\author{
X.F. Ma ${ }^{\mathrm{a}}$, H.L. Zhai ${ }^{\mathrm{a}}$, L. Zuo ${ }^{\mathrm{a}}$, W.J. Zhang ${ }^{\mathrm{a}}$, S.S. Rui ${ }^{\mathrm{b}}$, Q.N. Han ${ }^{\mathrm{c}}$, J.S. Jiang ${ }^{\mathrm{a}, *}$, C.P. Li ${ }^{\mathrm{d}}$, G.F. Chen ${ }^{\mathrm{d}}$, \\ G.A. Qian ${ }^{\mathrm{e}, \mathrm{f}, *}$, S.J. Zhao ${ }^{\mathrm{a}}$ \\ ${ }^{a}$ Sino-French Institute of Nuclear Engineering and Technology, Sun Yat-sen University, Zhuhai 519082, China \\ ${ }^{\mathrm{b}}$ AMPTL, Department of Mechanical Engineering, Tsinghua University, Beijing 100084, China \\ ${ }^{c}$ Aero-engine Thermal Environment and Structure Key Laboratory of Ministry of Industry and Information Technology, College of Energy and Power Engineering, Nanjing \\ University of Aeronautics and Astronautics, Nanjing 210016, China \\ ${ }^{\mathrm{d}}$ Materials \& Manufacturing Qualification Group, Corporate Technology, Siemens Ltd., China, Beijing 100102, China \\ e State Key Laboratory of Nonlinear Mechanics (LNM), Institute of Mechanics, Chinese Academy of Sciences, Beijing 100190, China \\ ${ }^{\mathrm{f}}$ School of Engineering Science, University of Chinese Academy of Sciences, Beijing 100049, China
}

\section{A R T I C L E I N F O}

\section{Keywords:}

Inconel 718

Selective laser melting

Microstructure

Fatigue short crack growth

In-situ SEM

\begin{abstract}
A B S T R A C T
The influence of orientation and temperature on fatigue short crack propagation behavior of Inconel 718 alloy was studied at both $25{ }^{\circ} \mathrm{C}$ and $650{ }^{\circ} \mathrm{C}$ by in-situ fatigue testing under scanning electron microscope. The fatigue crack growth rates (FCGR) showed evident dependence on orientation at both temperatures, following: $\mathrm{XZ}<\mathrm{X}<\mathrm{Z}$. The FCGR difference of XZ and Z orientation became less pronounced at $650{ }^{\circ} \mathrm{C}$. Fatigue cracks exhibited commonly transgranular fracture at both temperatures, with enhanced FCGR at $650{ }^{\circ} \mathrm{C}$. Microstructurally short crack propagation showed evident fluctuations, which were closely related to the blocking effects of grain boundaries.
\end{abstract}

\section{Introduction}

Additive manufacture (AM) has been attracting more and more attention as a revolutionary technique which combines great efficiency, critical manufacturing possibilities, and economic superiority. In recent decade, AM techniques have been widely studied for applications in the components of aerospace, biomedical, automobile, marine and so on [1]. It enables people to fabricate components with more complex geometry and hybrid microstructures. In spite of the prosperity of AM in recent years, there still remain some issues, such as unexpected porosity, surface defects, residual deformation caused by thermal history, and anisotropic mechanical properties attributed to its layer-bylayer build-up process. Industrial applications of AM techniques are still impeded by these imperfections, which must be considered for all possible service conditions in comparison with its conventional counterpart. Among the alloys made by AM, Inconel 718 alloy (IN718) fabricated by selective laser melting (SLM) has been of rising interests in recent years, due to its superior mechanical properties and corrosion resistance.

Tanja et al. [2] compared the tensile properties of IN718 alloy fabricated by SLM in different orientations with the forged and cast IN718 alloys, suggesting that the SLM made alloy has superior or equal strength compared with the forged one. Derek et al. [3] studied IN718 alloy made by direct metal laser sintering (DMLS) technique, showing that the quasi-static mechanical properties are similar to those of the forged, but the microstructural porosity and inhomogeneity is more notable. Regarding the fatigue property of IN718 alloy by AM, which is more sensitive to microstructural variation, surface condition, and residual deformation etc. formed by AM process, it is not yet well understood. Gribbbin et al. [4] compared the low cycle fatigue (LCF) properties of IN718 alloy fabricated by AM, hot isostatic pressed (HIP), and wrought process. They pointed out that the AM made alloy has longer LCF life than the wrought ones at low strain amplitudes. Konečná et al. [5] studied the fatigue crack growth rates and fatigue crack paths of SLM IN718 alloy in both the threshold region and the Paris region, revealing that the lower fatigue crack growth (FCG) resistance was related to low boron content, finer microstructure and residual stress. Zhang et al. [6] compared the fatigue properties of SLM IN718 alloy with two scanning strategies, i.e. bidirectional scanning without and with a $90^{\circ}$ rotation between the successive layers, suggesting that

\footnotetext{
* Corresponding authors at: State Key Laboratory of Nonlinear Mechanics (LNM), Institute of Mechanics, Chinese Academy of Sciences, Beijing 100190, China (G.A. Qian).

E-mail addresses: jiangjsh3@mail.sysu.edu.cn (J.S. Jiang), qianguian@imech.ac.cn (G.A. Qian).
} 
superior fatigue strength of the former one is attributed to the variation of grain size and texture feature.

The distinct directional microstructure formed by the typical AM process of layer-by-layer material build-up is crucial to the anisotropic mechanical properties. In fact, the anisotropy makes it difficult to evaluate the fatigue strength and failure mechanism of SLM IN718 alloy. Konečná and Nicoletto et al. [5] studied the orientation dependence of fatigue properties and found that the build orientation corresponded to the lowest fatigue strength, consistent with the previous studies [8]. The study of Zhang and Niu et al. [7] on IN718 alloy after an industrial standard heat treatment yielded similar results. Deng and Moverare et al. [8] examined IN718 alloy in both as-printed and post heat-treated conditions and found that the anisotropy was not completely removed by heat treatment. Recently, Spear et al. [9] studied the orientation dependence on the high-cycle fatigue life of IN718 alloy by laser powder bed fusion, indicating that surface roughness and subsurface defects controlled the fatigue life for different building orientations. Hu et al. [10] reported that the long fatigue crack growth (FCG) rate was affected by orientation in the near threshold region but negligible in the Paris region of SLM Inconel 625 alloy. It is reported that for non-HIPed specimen, the low-cycle and high-cycle fatigue properties are shorter in the vertically built specimen than the horizontally built specimen, due to more porosity perpendicular to the build direction. The orientation effects would be more pronounced for as-printed surface due to higher probability of surface/subsurface defects and larger surface roughness, which are the primary influence factors of the crack initiation and crack propagation process, especially in the high-cycle and very high cycle fatigue issues. Similar results have been reported in IN718 alloy and similar SLM alloys [1,9,11].

Despite the above finding, the effects of orientation on the fatigue life of IN718 alloy by SLM were not fully understood. This is partially because that fatigue life not only depends on the stages of crack initiation and long fatigue crack propagation, but the short crack growth usually takes up a large portion of fatigue life. The authors are unaware of any report on the experimental studies of short crack propagation behavior in SLM IN718 alloy, either by in-situ or ex-situ technique. Nevertheless, the previous studies on wrought IN718 alloy $[12,13]$ can add lights to understand this issue. Furthermore, the temperature is known to be an important factor in altering the deformation mechanism and fatigue crack propagation manner of nickel-based superalloy. For instance, Ma and Shi et al. [14,15] reported that octahedral crystallographic cracking (Stage I) is the preferred crack propagation at low temperatures and high frequencies $(>3 \mathrm{~Hz})$, whereas non-crystallographic fracture is dominated at higher temperatures and high frequencies. The effect of temperature on IN718 alloy makes it harder to evaluate the fatigue crack propagation behavior associated with microstructure evolution and dislocation activities [15]. In contrast, there are few published studies that address the above issues for IN718 alloy fabricated via SLM. In view of this lack of information, the present work is aimed to establish the influence of printing orientation and temperature on the fatigue short crack propagation behavior of IN718 alloy.

As a powerful tool for charactering surface morphology and elementary composition of materials, in-situ scanning electron microscope (SEM) technique has been increasingly used to study the effects of microstructure on mechanical properties, especially fatigue performance. This technique can provide high resolution images of the material surface throughout fatigue testing process, in which fatigue crack initiation and propagation mechanism associated with microstructure evolution under either room or high temperatures can be investigated. Wang et al. [16] evaluated the fatigue crack growth rates of magnesium alloy by capturing a series of SEM images to understand the strain localization during fatigue crack initiation and early crack propagation. Shi and Ma et al. [15,17] studied the fatigue small crack behavior of nickel-based superalloys, to address the associated slip activities and the interaction of crack tip with local grain boundaries and carbides, considering the effects of crystal orientation and temperature. Jiang et al. [18] characterized the crack initiation behavior at early stage in a disk superalloy with digital image correlation (DIC) technique [18]. The crack propagation behavior of a high entropy alloy (HEA) [19] was studied using in-situ SEM observations to reveal the deformation mechanisms in the crack tip plastic zone, including slip and twinning. Insitu SEM fatigue testing was also employed to study the fatigue crack closure behavior and fretting fatigue behavior of single crystal superalloy with different secondary orientation, which provides good insights into the underlying mechanism, especially when combined with crystal plasticity simulation for instance [20].

In this paper, in-situ fatigue tests were performed in a specially designed SEM chamber to study the fatigue crack propagation behaviors of additive manufactured IN718 alloy by SLM at $25^{\circ} \mathrm{C}$ and $650{ }^{\circ} \mathrm{C}$. Fatigue specimens with the loading axis along $0^{\circ}, 45^{\circ}$, and $90^{\circ}$ off the build orientation (denoted as $\mathrm{Z}, \mathrm{XZ}$, and $\mathrm{X}$, respectively) were studied to reveal the effects of orientation on fatigue crack behavior. The interaction between fatigue short crack and local microstructures related to printing direction were studied in details. The influence of temperature and specimen orientation on fatigue crack growth rates was analyzed and discussed.

\section{Materials and experimental procedure}

The material used in this study is an additively manufactured nickelbased superalloy IN718, which has been frequently reported on the relationship between its microstructure features and mechanical properties $[5,6,21]$. The IN718 alloy was manufactured by selected laser melting of IN718 powder using an EOS M280 additive manufacture machine, which is a SLM system from EOS GmbH (Germany made). To obtain the samples with maximum density and no evident cracking or delamination, the SLM process parameters were optimized as: laser power of $285 \mathrm{~W}$, scan speed of $960 \mathrm{~mm} / \mathrm{s}$, and hatching spacing of $100 \mu \mathrm{m}[6,21]$. The pre-heating temperature was selected as $80{ }^{\circ} \mathrm{C}$. The manufacturing process was conducted under argon atmosphere with $0.1 \%$ oxygen. As-received IN718 spherical powder with a size of $15 \mu \mathrm{m}$ to $53 \mu \mathrm{m}$ was used. Finally, the relative density of IN718 block was larger than 99.5\%. The chemical compositions of IN718 alloy in this study is (in wt.\%) given in Table $1[5,6,21]$.

A rectangular block was manufactured by selected laser melting of IN718 powder with alternate scanning directions, that is, first along $\mathrm{X}$ direction and then along Y direction and so on. The IN718 alloy by SLM was then subjected to annealing at $550{ }^{\circ} \mathrm{C}$ for $8 \mathrm{~h}$ to remove the residual stress. The block of IN718 alloy was used to fabricate plate specimen with a dog-bone shape, which has a $2.5 \mathrm{~mm}$ by $0.4 \mathrm{~mm}$ gauge cross section as shown in Fig. 1. A U-shape side-notch was specially designed at the center of gauge section for each specimen to study the crack initiation and propagation behavior. The notch has a depth of about $50 \mu \mathrm{m}$ and diameter of about $35 \mu \mathrm{m}$ for each specimen. The scope of the present experiment included specimens in three typical orientations, i.e. X, XZ, and Z. The definition of each orientation was shown in Fig. 2, in which the orientation along the build-up direction was denoted as $\mathrm{Z}$.

In order to expose the prevailing microstructure for in-situ investigation under SEM, the surface of fatigue specimen was ground to 1500 grit sand paper, polished down to $1 \mu \mathrm{m}$ diamond paste, rinsed and etched prior to fatigue test. The etchant is an aqueous solution of $4.5 \mathrm{~g}$ $\mathrm{CuSO}_{4}+20 \mathrm{~mL} \mathrm{HCl}+20 \mathrm{~mL} \mathrm{H}_{2} \mathrm{O}$. The fatigue crack propagation tests

Table 1

The chemical compositions of Inconel 718 alloy (in weight percent, wt\%).

\begin{tabular}{llllllll}
\hline & $\mathrm{Cr}$ & $\mathrm{Fe}$ & $\mathrm{Nb}$ & $\mathrm{Mo}$ & $\mathrm{Co}$ & $\mathrm{Ti}$ & $\mathrm{Al}$ \\
\hline $\mathrm{wt} \%$ & 18.8 & 18.6 & 5.36 & 3.14 & 0.38 & 0.97 & 0.50 \\
& $\mathrm{Cu}$ & $\mathrm{W}$ & $\mathrm{V}$ & $\mathrm{Mn}$ & $\mathrm{Zr}$ & $\mathrm{C}$ & $\mathrm{Ni}$ \\
$\mathrm{Wt} \%$ & 0.16 & 0.09 & 0.07 & 0.10 & 0.02 & 0.07 & $\mathrm{Bal}$.
\end{tabular}




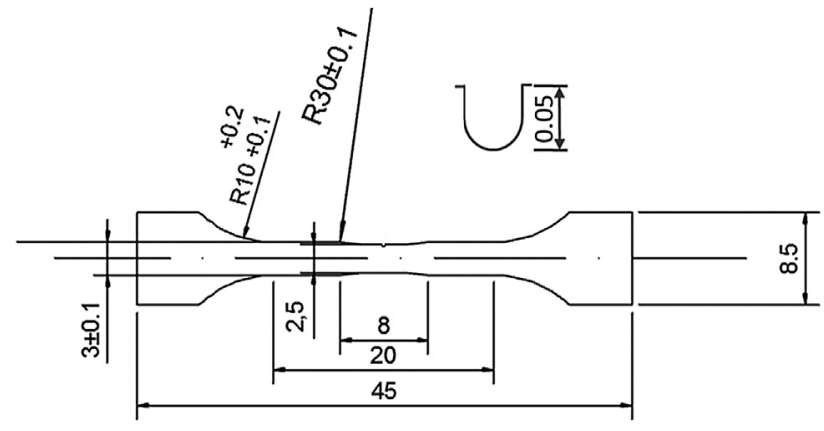

Fig. 1. Fatigue specimen geometry used in the fatigue testing (in $\mathrm{mm}$ ).

were performed in the vacuum chamber of SEM with a specially designed servo-hydraulic experimental system (Fig. 3), which can generate static or cyclic loading of $\pm 1 \mathrm{kN}$ maximum capacity and a displacement scope of $\pm 25 \mathrm{~mm}$. The maximum cyclic loading frequency is $10 \mathrm{~Hz}$. To realize successive sampling of the $960 \times 1280$ frames of images under secondary electronic mode, a direct memory access type A/D converter is used to transmit the signal of the SEM to the computer. The accelerating voltage of the SEM was $15 \mathrm{kV}$. Elevated temperature is achieved by induction heating with a maximum of $800{ }^{\circ} \mathrm{C}$ and a control resolution of $1{ }^{\circ} \mathrm{C}$. The temperature of the sample surface was monitored and regulated by the feedback from a thermal couple attached to the gauge section of the sample.

Since there are multiple fatigue samples for different orientations and temperatures, all the specimens were numbered specially. For example, the specimen $\mathrm{X} 25$ represented the $\mathrm{X}$ oriented specimen tested at $25{ }^{\circ} \mathrm{C}$, and the specimen XZ650 represented the XZ oriented specimen tested at $650{ }^{\circ} \mathrm{C}$. Similar denotation was used for the other fatigue specimens. Stress controlled fatigue tests with a stress ratio of $\mathrm{R}=0.1$

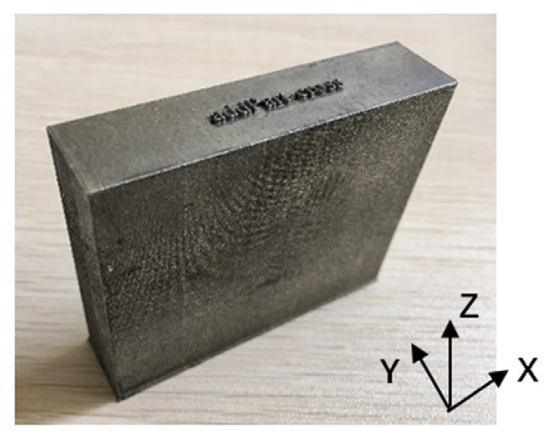

HT: $550^{\circ} \mathrm{C}, 8 \mathrm{~h}$ annealing

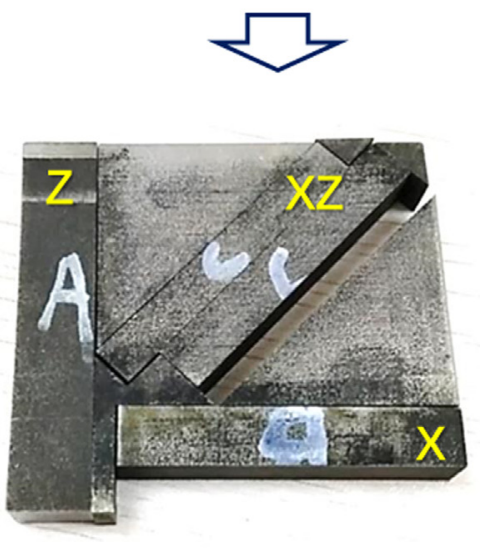

at $25{ }^{\circ} \mathrm{C}$ and $650{ }^{\circ} \mathrm{C}$ were performed. Constant maximum stresses were adopted (890 MPa for $25{ }^{\circ} \mathrm{C}$ and $735 \mathrm{MPa}$ for $650{ }^{\circ} \mathrm{C}$ ) all through each fatigue test to study the fatigue crack propagation behavior. The stress level was specially adopted so that the samples at $25^{\circ} \mathrm{C}$ and $650{ }^{\circ} \mathrm{C}$ have similar maximum strain value during cyclic loading. The sinusoidal signal of loading wave was utilized. Each fatigue test was tested under a loading frequency of $2 \mathrm{~Hz}$. The tests were paused at different selected loading cycles, with an interval between 10 cycles and 1000 cycles, to capture SEM images which are used to analyze the interaction between fatigue crack and local microstructures, e.g. grain boundary. The image scanning was performed under secondary electronic mode, with the load held at half of the maximum stress. In consequence, the crack growth rates can be estimated from the measured crack length at intervals. By comparison of the crack propagation process at adjacent moments, the correlation between local microstructures and fatigue cracking manner can be analyzed.

\section{Results}

The in-situ SEM observation makes it possible to study the fatigue crack behavior at the very early stage. For all in-situ micrographs hereafter, the loading axis is along the vertical direction. The fatigue crack propagation behavior for different oriented samples (X, XZ and $\mathrm{Z}$ ), at both temperatures, were compared and the underlying mechanisms were discussed.

\subsection{Microstructure of IN718 alloy fabricated by SLM}

Fig. 4 shows the microstructures of the IN718 alloy fabricated by SLM before fatigue test. Fig. $4 \mathrm{a}, \mathrm{c}$ and e correspond to the microstructure of fatigue specimens with longitudinal axis along $\mathrm{X}, \mathrm{Z}$, and $\mathrm{XZ}$ orientation (the vertical direction of the micrographs), respectively. For
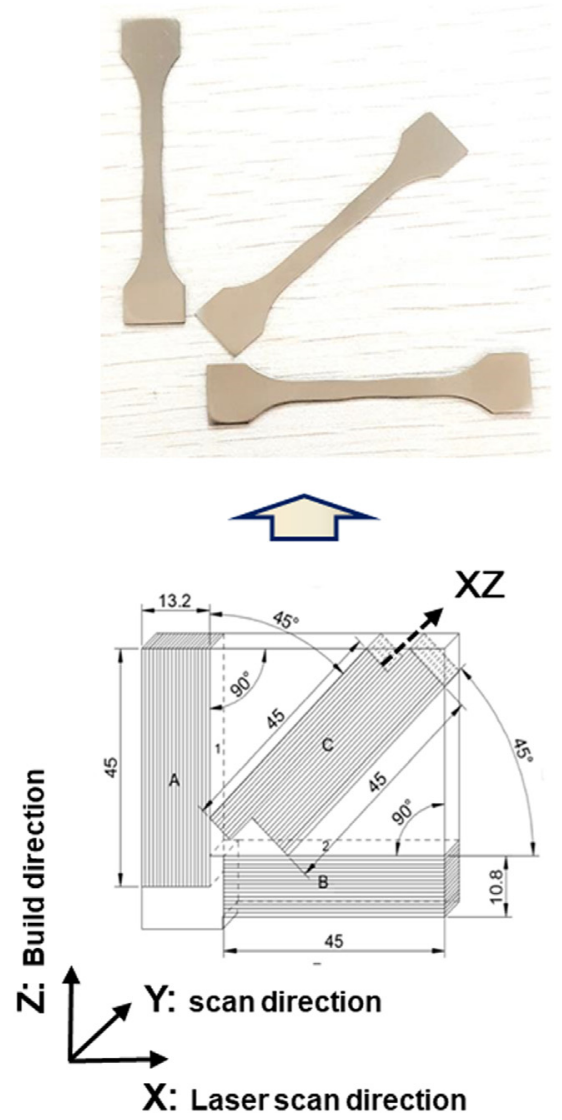

Fig. 2. Fatigue test specimens cut from IN718 alloy block manufactured by selective laser melting: three orientations of $\mathrm{X}$, $\mathrm{XZ}$, and $\mathrm{Z}$ were studied. 

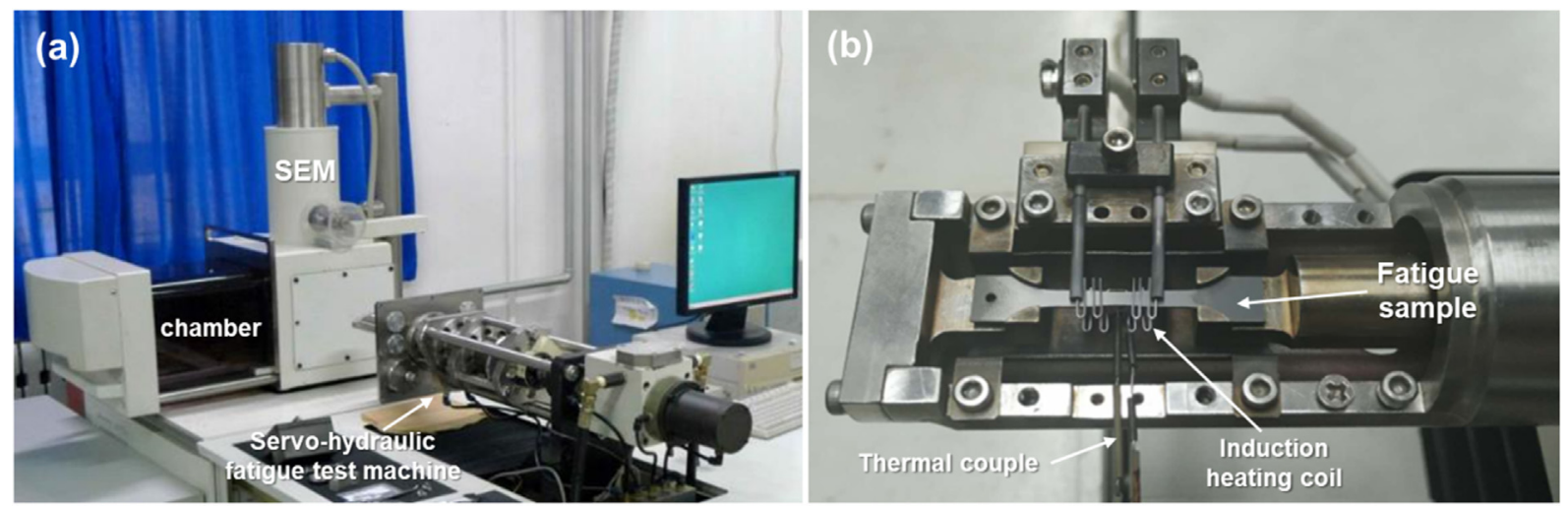

Fig. 3. In-situ fatigue testing system with scanning electronic microscope for structural alloys for both room temperature and high temperature: (a) scanning electronic microscope; (b) fatigue sample loading unit for high temperature.


Fig. 4. Microstructures of IN718 alloy fabricated by selected laser melting: top views of (a) X oriented specimen; (b) X oriented specimen, high magnification of 'b'; (c) Z oriented specimens; (d) Z oriented specimens, high magnification of ' $d$ '; (e) XZ oriented specimen; (f) XZ oriented specimen, high magnification of ' $\mathrm{f}$ '. 
$\mathrm{X}$-oriented specimen in Fig. 4a, the long columnar grains intersecting with each other are consistent with the solidification surface morphology by the X-Y alternative printing process [1]. In the top-view of the X-oriented specimen (X-Y plane), the width of columnar grains is about $100 \mu \mathrm{m}$. A high magnification view is shown in Fig. 4b, where melt poor border was noticed at ' 1 ' and fine precipitates were observed in the junction region between adjacent laser tracks [5].

Fig. $4 c$ is the top-view of the Z-oriented specimen (Z-Y plane). Multiple melt pools with almost semi-elliptical shape were observed, for which the average width was about $120 \mu \mathrm{m}$, with the applied hatch spacing being $100 \mu \mathrm{m}$. In addition, there is a partial remelting zone (PRZ) with a width almost $20 \%$ of the hatch spacing between the adjacent laser tracks, which is consistent with the work of Konečná et al [21]. For the high magnification view in Fig. 4d, near the melt pool border (marked by ' 3 '), multiple cells aligned along the radical direction, which were formed during the growth from the melt pool boundary via cellular growth solidification during SLM [21]. In the process of cooling solidification of the liquid metal, due to the cooling effect of substrate, heat mostly dissipates in the negative Z-direction [5]. Due to the highest temperature gradient and solidification rate in the Z-direction, grains preferentially grow with the directional selection to form the dendrites [22].

Fig. 4e shows the top-view of the $\mathrm{XZ}$ oriented specimen, which is similar to the $\mathrm{Z}$ oriented sample in Fig. 4c. High magnification view in Fig. 4f shows the fine microstructure at the centerline of laser track, marked as ' 4 '. It was characterized by very small precipitates in the $\gamma$ matrix, which is consistent with the IN718 study reported by Zhang et al. [5]. At the site ' 5 ', elongated cell grains aligned radially, along the heat flux direction, were observed. Defects such as small microshrinkages between the connected layers were just occasionally found in the microstructure. Similarly, small gas pores manifesting themselves as black round spots were observed only locally (Fig. 4a and e) [5]. The observed layer structure and melt pool tracks are consistent with the typical features of similar alloys $[23,24]$ fabricated by SLM.

Fig. 5 shows the EBSD characterization of the three orthogonal planes of the SLM IN718 alloy block [21]. The grain orientation was connected to the normal directions of each plane. It is seen that the grain orientation distribution shows evident difference on the three planes. On the Z-Y plane (top surface of Z specimen), directional columnar grains with length of several hundred microns were formed, with width close to the hatch distance of $100 \mu \mathrm{m}$ [25]. The grains on the Z-Y plane mostly appear red, following a cube texture (rotated by $45^{\circ}$ about $\mathrm{X}$ ) with $\left\langle\begin{array}{lll}0 & 1\end{array}\right\rangle$ along $\mathrm{X}$. The alternate scanning strategy provided fewer remelted grains with optimal crystal orientation because the heat flux direction rotated with the laser track between the successive layers. Epitaxial growth along $\left\langle\begin{array}{llll}0 & 0 & 1\end{array}\right\rangle$ orientation was preferred compared

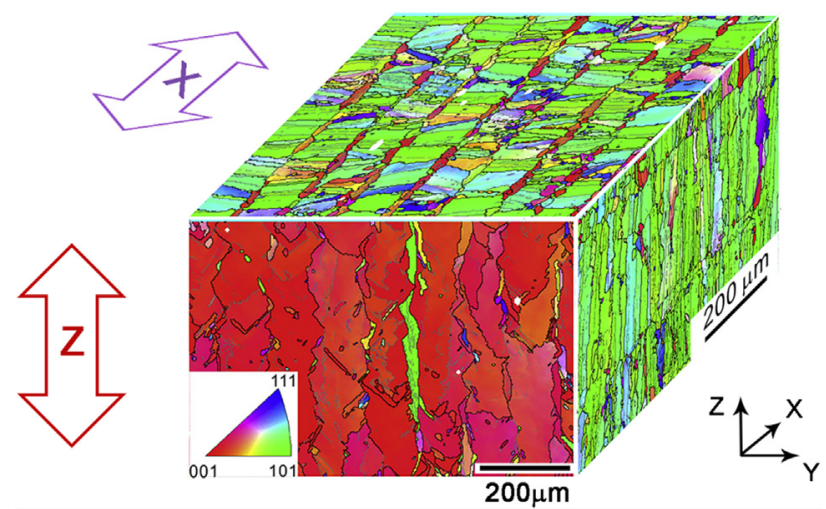

Fig. 5. EBSD characterization of grain orientation maps taken on the three planes of the selective laser melting fabricated IN718 alloy using bidirectional scanning strategy $(\mathrm{X}-\mathrm{Y})$ with a rotation between the successive layers, with $\mathrm{Z}$ being the build-up direction [21]. with crystal nucleation in this case [21], leading to directional grain structures. A few columnar grains with different orientations were observed, due to the local disturbance of heat flux in the melt pool [21]. The maximum cube-texture intensity on Z-Y plane is about 19 , according to the authors' previous study [21]. The strong texture due to the rotation of scanning direction by $90^{\circ}$ was also reported in tantalum fabricated by SLM [25].

\subsection{Fatigue crack propagation behavior of IN718 alloy at $25{ }^{\circ} \mathrm{C}$}

Fig. 6 shows the crack initiation and propagation behavior of specimen X25 (X orientation, at $25^{\circ} \mathrm{C}$ ) after different fatigue loading cycles. Fig. 6a shows the onset of fatigue short crack, which initiated from the notch root after 706 cycles due to local stress concentration. The crack proceeded along the horizontal direction till 6303 cycles (Fig. 5b). After 10,004 cycles, the crack propagation was shifted evidently to along slip bands which were about $45^{\circ}$ inclined (Fig. 6c). The crack showed apparent tortuosity and then penetrated the grain boundary in a transgranular manner. On the fatigue crack mating surface, some particles can be observed, for instance in Fig. $6 \mathrm{c}$ and $6 \mathrm{e}$, which were carbides indicated by SEM-EDS analysis. In Fig. 6e, it is shown that the crack front was impeded by the grain boundary, which took about $1000 \mathrm{cy}-$ cles to go through the grain boundary. It caused remarkable deceleration of fatigue crack growth. Similarly, in Fig. 6 f, intensive slip bands were observed when the crack was approaching another grain boundary, and the crack was arrested by grain boundary for 500 cycles. After another 2400 cycles, X25 specimen failed due to unstable crack propagation.

For the XZ25 specimen at room temperature, fatigue crack did not nucleate until 9408 cycles. Parallel slip bands were noticed ahead of crack tip, which interacted with the grain boundary as shown in Fig. 7a. Afterwards, the fatigue crack propagated along the slip bands and penetrated the grain boundary as shown in Fig. $7 \mathrm{~b}$. A remarkable decrease of FCGR was noticed when the crack approached the second grain boundary. The crack branched towards a carbide and bypass it to propagate against the grain boundary (Fig. 7c). The crack followed the grain boundary until it was blocked and bifurcation was noticed in Fig. 7d. Evident slip bands appeared in the associated grain and the crack propagated again in a transgranular way. The crack penetrated the upper grain boundary without change of propagation direction. A high magnification of the crack tip showed that the fatigue crack was impeded by a carbide (Fig. 7e). Bifurcation of crack was evidenced and a slip band appeared in front of the crack (Fig. 7e). The crack passed the carbide and continued to propagate. Afterwards, slip bands appeared and the primary crack merge into one of the slip band. The crack would shift to zig-zag mode which can increase the crack length more efficiently, as shown in Fig. 7f. A secondary crack (marked as '2') along slip bands occurred ahead of the primary crack (marked as ' 1 '), which coalesced with each other after another 1500 cycles. Accordingly, the fatigue crack growth accelerated dramatically, followed by catastrophic rupture.

Fig. 8 shows the in-situ observation results of Z25 specimen. Fatigue crack initiated at the notch root and slip bands were evidently observed in the adjacent grains as pointed out by arrows in Fig. 8b. Fatigue crack propagation proceeded along the slip bands as shown in Fig. $8 \mathrm{~b}$ and $\mathrm{c}$. While approaching the grain boundary nearby, slip activities ahead of fatigue crack tip was affected evidently, as shown by the curved crack path in Fig. 8d. There is an increase of crack tip opening displacement (CTOD) while the crack was arrested, as shown in Fig. 8e. After passing the grain boundaries, the fatigue crack exhibited fast propagation rate via crystallographic cracking manner, which coalescences with the microcracks ahead of crack tip, leading to the final rupture. It is noted that the maximum crack length tolerable in the Z-orientated specimen is smaller than those of $\mathrm{X}$ and $\mathrm{XZ}$ orientations. 


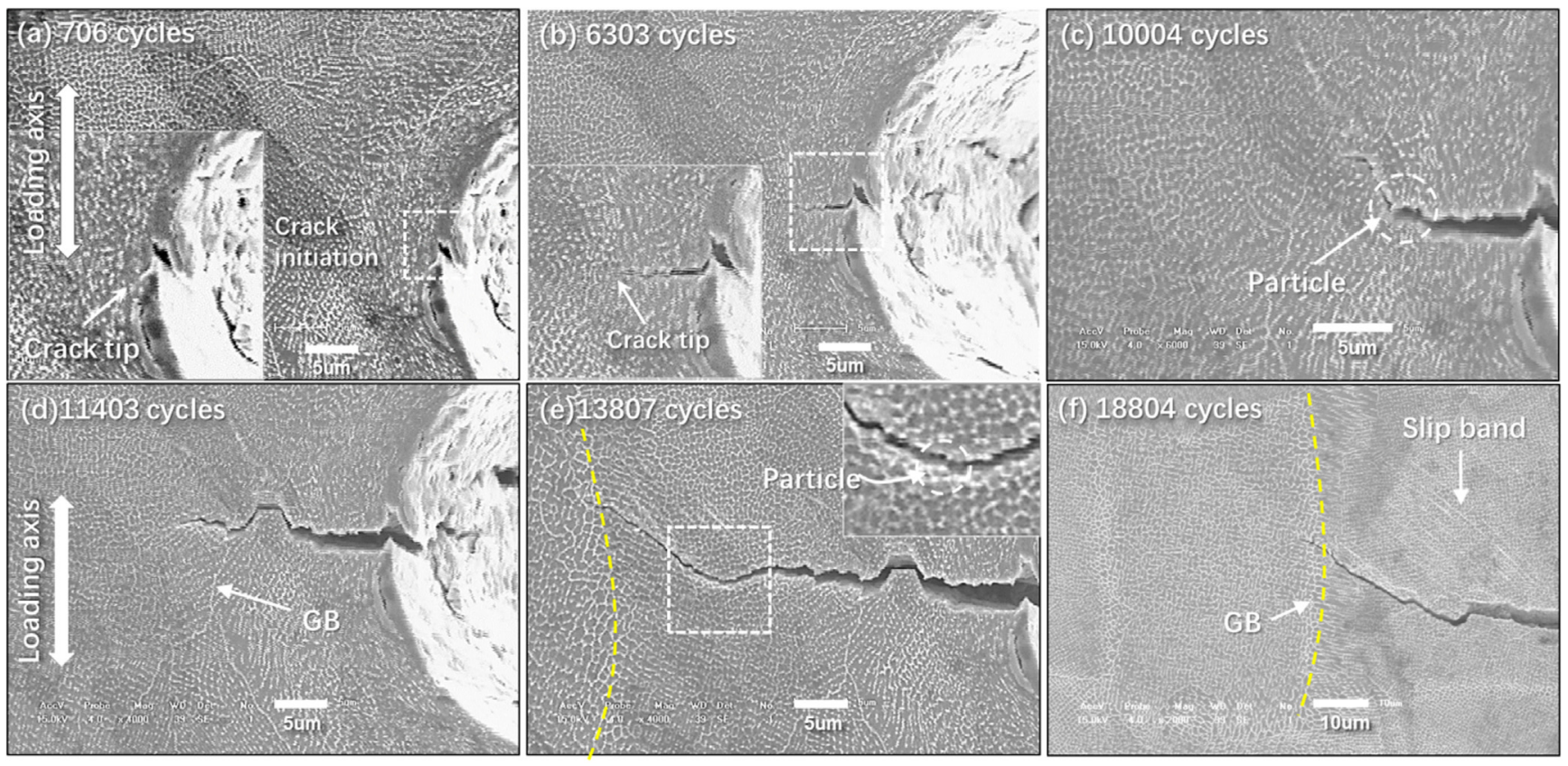

Fig. 6. Fatigue crack growth behavior of specimen $\mathrm{X} 25$ at $25^{\circ} \mathrm{C}$ (the loading axis is vertical, along the $\mathrm{X}$ orientation): (a) 706 cycles; (b) 6303 cycles; (c) 10,004 cycles; (d) 11,403 cycles; (e) 13,807 cycles; (f) 18,804 cycles.

\subsection{Fatigue crack propagation behavior of IN718 alloy at $650{ }^{\circ} \mathrm{C}$}

For the specimens at $650{ }^{\circ} \mathrm{C}$, in-situ observations of fatigue crack propagation have also been conducted. Fig. 9 shows the result of X650 specimen (X orientation, at $650{ }^{\circ} \mathrm{C}$ ), in which fatigue crack propagation preferred crystallographic way but tortuous, accompanied with slip bands (Fig. 9a). When the loading cycles came to 18,529 cycles, fatigue crack propagated horizontally until the crack tip encountered a grain boundary, as shown in Fig. 9b, which contributed to a remarkable decrease in FCGR. The following crack propagation in the grain followed a zigzag cracking manner (Fig. 9c). It took about 400 cycles for the crack to penetrate the grain boundary. In Fig. $9 d$, the crack encountered another grain boundary. Intensive slip bands were observed ahead of the crack tip. The fatigue crack preceded along the slip bands, forming a zigzag cracking path as shown in Fig. 9e. It is common in the X-orientation specimen that the grain boundaries act as barriers to fatigue crack propagation [10], which generally contributed to a decrease of the FCGR. In Fig. 9f, fatigue crack propagation was evidently impeded by grain boundary as arrowed, which was associated with a dramatic increase of fatigue crack tip opening displacement. Subsequently fatigue crack penetrated the grain boundary to promote fatigue crack growth, resulting in the ultimate failure.

For the XZ650 specimen as shown in Fig. 10, the fatigue crack propagation after initiating from notch root showed crystallographic


Fig. 7. Fatigue crack growth behavior of specimen XZ25 at $25^{\circ} \mathrm{C}$ (the loading axis is vertical, along the XZ orientation): (a) 9408 cycles; (b) 11,002 cycles; (c) 11,504 cycles; (d) 12,281 cycles; (e) 12,844 cycles (f) 17,000 cycles. 


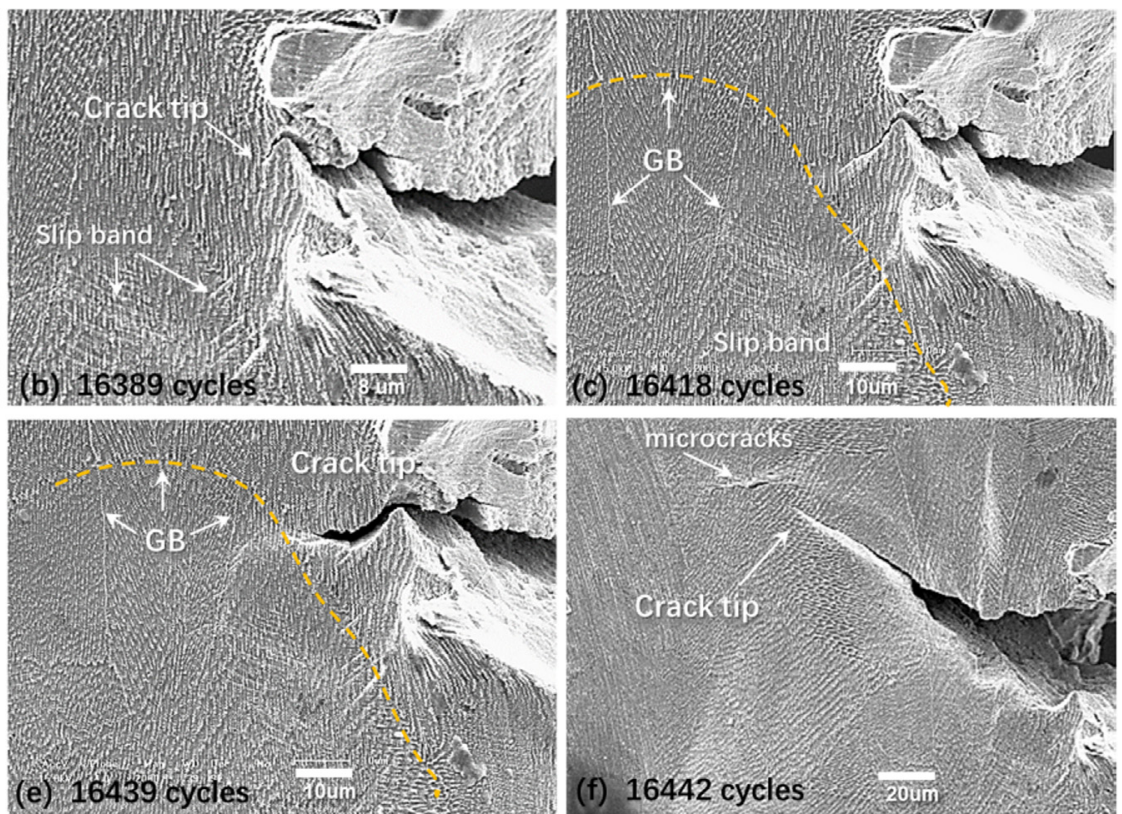

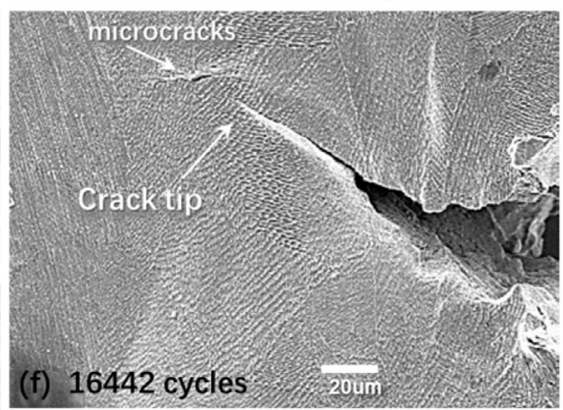

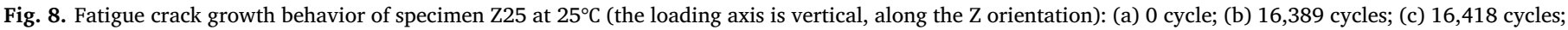
(d) 16,432 cycles; (e) 16,439 cycles; (f) 16,442 cycles.

cracking manner, with slip bands ahead of crack tip (Fig. 10a). In Fig. 10b, evident slip bands emerged on both sides of fatigue crack. The fatigue crack tip was branched due to interaction with a grain boundary, in which the crack opening displacement was slightly larger than usual in Fig. 10b. In Fig. 10c, fatigue crack was evidently blocked by a columnar grain boundary and secondary cracking along grain boundary was noticed, which caused a remarkable increase of the CTOD. In the adjacent region ahead of crack tip, micro-cracks occurred due to local severe plastic deformation. This phenomenon was even more evident in Fig. 10d when the crack met another grain boundary. Fatigue crack tip altered its direction to be along the vertical grain boundary and the crack opening displacement was quite large, indicating severe impeding effect. It took another 44 cycles for the crack to pass the grain boundary, as shown in Fig. 10e. A high magnification view of the crack tip showed cracking along the duplex slip bands, which is beneficial to decrease crack propagation rate due to tortuosity. In Fig. 10f, after 9938 loading cycles, fatigue crack passed the previous grain boundary and continued along one of the slip direction. Faceted steps were disclosed on the fracture surface behind the crack tip, which coincide with the observed crystallographic fracture mode in this study and in similar alloys $[12,13]$. The crack opening displacement was extremely large in Fig. 10f, which led to a subsequent acceleration of FCGR and final failure after another 10 cycles.

Fig. 11 shows the in-situ observation results of specimen Z650 (the building orientation, at $650{ }^{\circ} \mathrm{C}$ ). In Fig. $11 \mathrm{a}$, it is evident that fatigue crack preferred crystallographic cracking, which is consistent with the
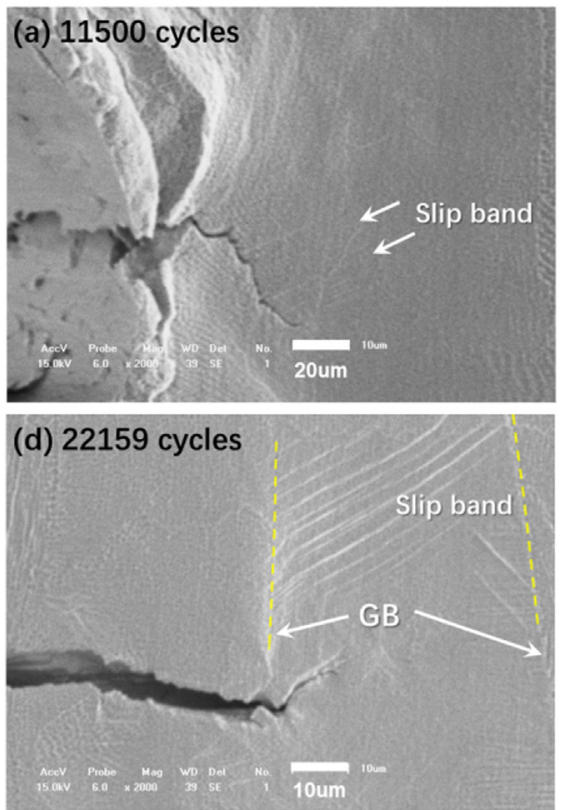
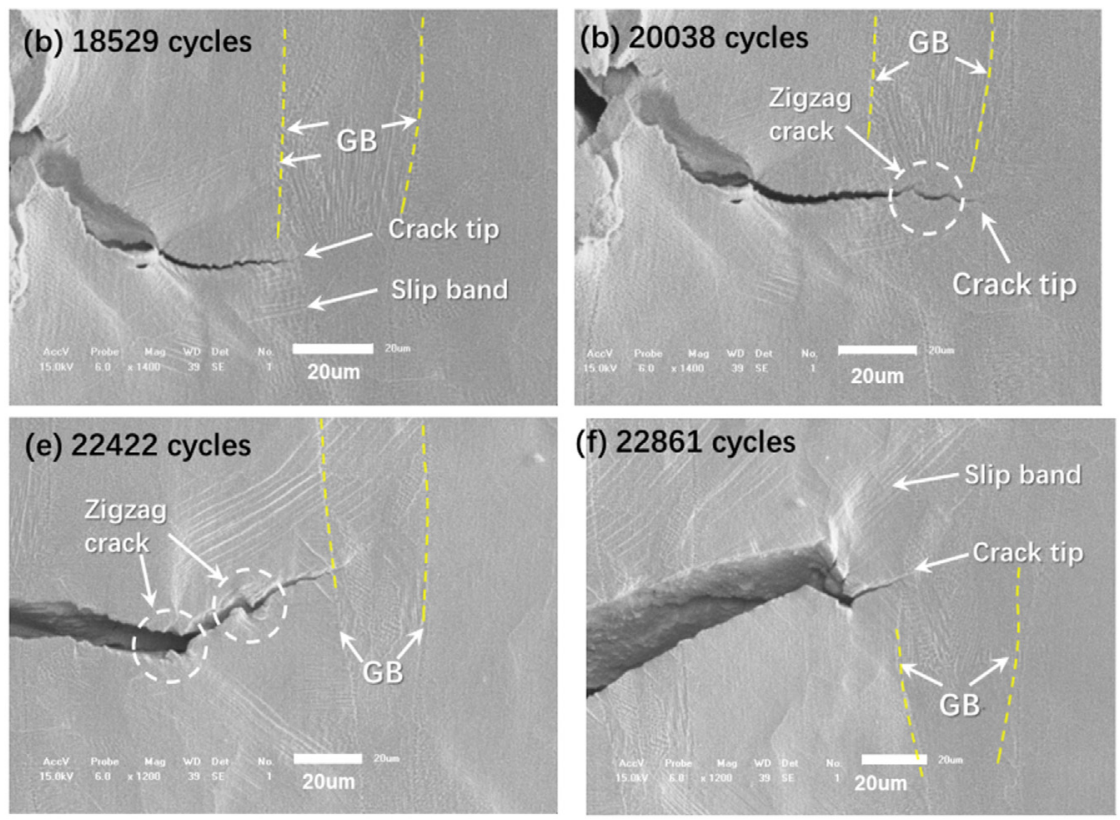

Fig. 9. Fatigue crack growth of specimen $\mathrm{X} 650$ at $650^{\circ} \mathrm{C}$ (the loading axis is vertical, along the $\mathrm{XZ}$ orientation): (a) 0 cycles; (b) 6379 cycles; (c) 16,700 cycles; (d) 17,990 cycles; (e) 22,308 cycles; (f) 22,861 cycles. 

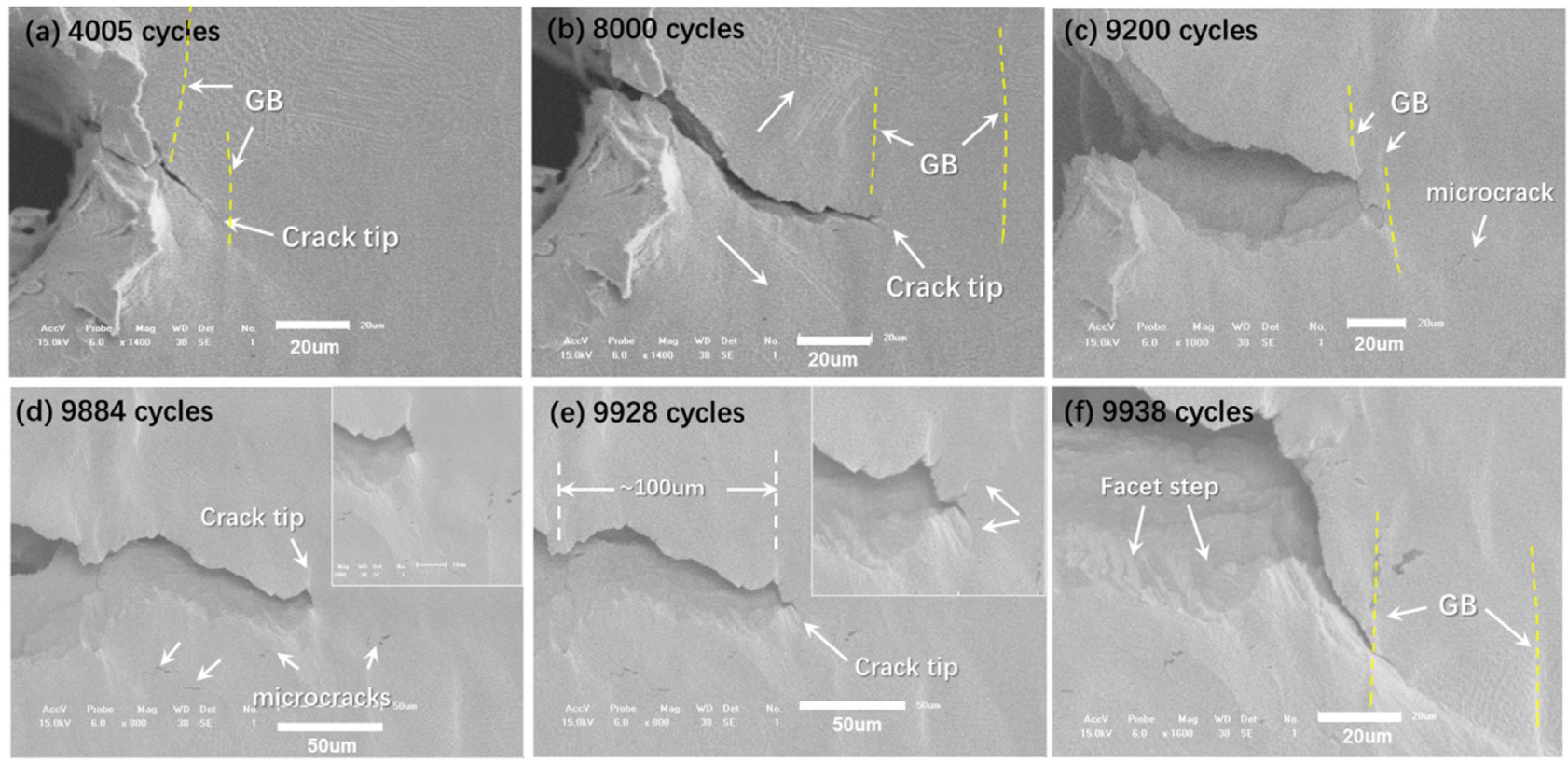

Fig. 10. Fatigue crack growth of specimen $X Z 650$ at $650^{\circ} \mathrm{C}$ (the loading axis is vertical, along the $X Z$ orientation): (a) 4005 cycles; (b) 8000 cycles; (c) 9200 cycles; (d) 9884 cycles; (e) 9928 cycles; (f) 9938 cycles.

other samples in this study. While the crack approached grain boundary, interaction of slip band with grain boundary was observed. Cracking formed along the slip band and a kink was observed at the grain boundary in Fig. 11b. The crack still followed crystallographic direction in Fig. 11c, and there is evident increase in crack opening displacement. While the crack tip was arrested at the grain boundary in Fig. 11d, the crack opening became more evident. It took another 300 cycles for fatigue crack to overcome the grain boundary to enter the next grain (Fig. 11e). And out of plane deformation was noticed. Fig. 11f shows that the crack became evidently blunt and remarkably opened, which was subsequently followed by the final rupture.

\subsection{Fatigue fracture surfaces}

The fracture surfaces of all fatigue specimens have been examined under scanning electronic microscope, to disclose the fracture mechanism during fatigue crack propagation. Fig. 12a shows the overall rough fracture surface of X25 specimen. A high magnification of site ' $b$ ' in Fig. 12a was shown in Fig. 12b, indicating river patterns fracture mode. Evident dense striations were revealed by high magnification observation, which is indicative of plastic blunting mechanism assisted crack propagation. In the fast propagation region ('c' in Fig. 12a), facets and secondary cracks were noticed. Fig. 12d-f and Fig. 12g-i show the fracture surfaces of XZ25 and Z25 specimens, respectively. Faceted fracture is more evident in XZ25 and Z25. Fig. 12e shows striation like


Fig. 11. Fatigue crack growth behavior of specimen $\mathrm{Z} 650$ at $650^{\circ} \mathrm{C}$ (the loading axis is vertical, along the build orientation, i.e. $\mathrm{Z}$ orientation): (a) 1001 cycles; (b) 1219 cycles; (c) 1425 cycles; (d) 1689 cycles; (e) 1967 cycles; (f) 2389 cycles. 

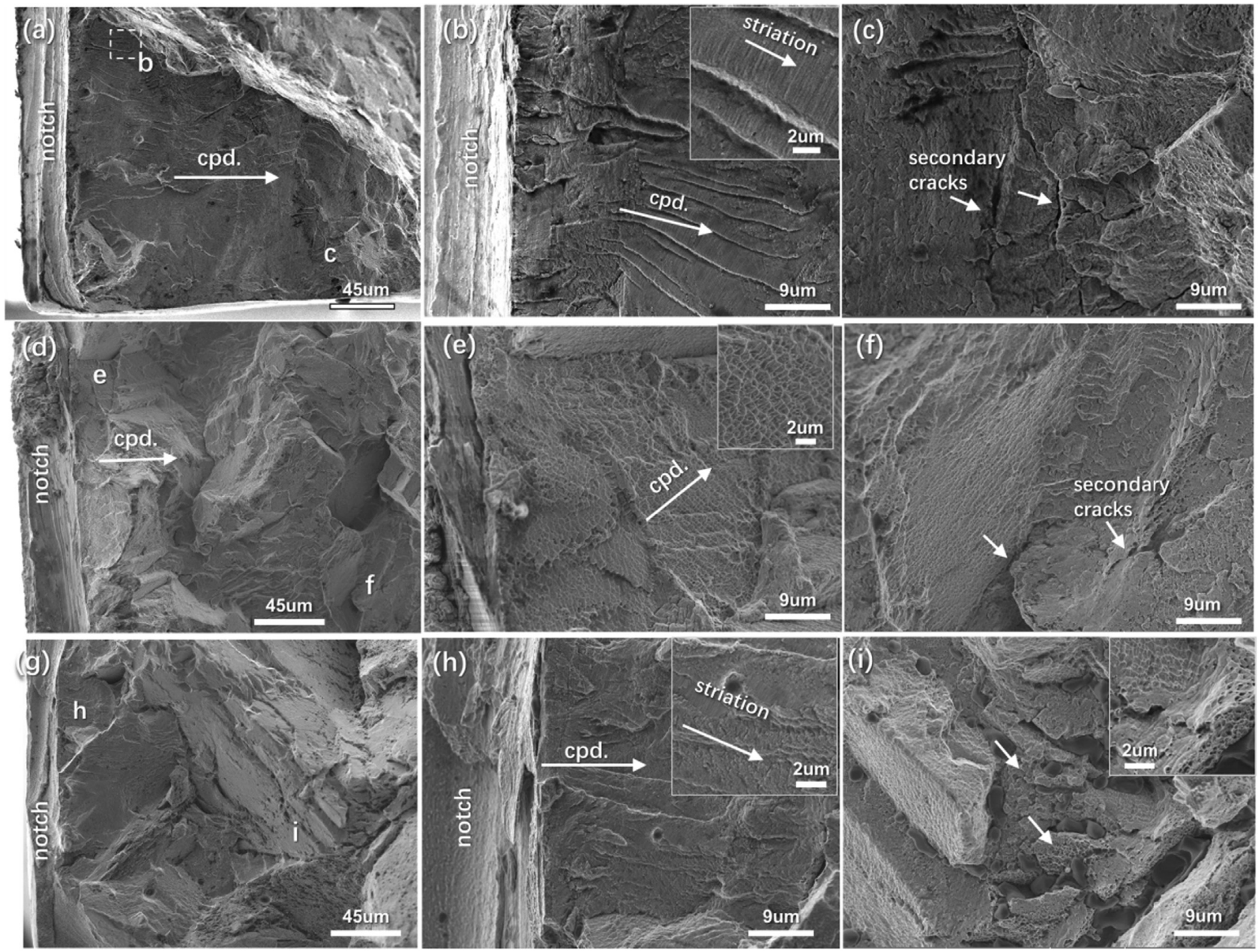

Fig. 12. Fatigue fracture surfaces observation of IN718 alloy showing the effects of orientation at $25{ }^{\circ} \mathrm{C}$ : (a)-(c) X25 specimen; (d)-(f) XZ25 specimen; (g)-(i) Z25 specimen.

structure with evident plastic deformation. In the fast propagation region ' $\mathrm{f}$ ' (Fig. 12f), large octahedral planes were evidently formed, with secondary cracks occurring at the deflection site. For Z25 specimen, striations were also observed in Fig. 12h. Porosity and dimples were evidently observed in the high $\Delta \mathrm{K}$ region in Fig. 12i. It is known that the defects, such as porosity, are more likely to form between printing layers during the selecting laser melting process. That is why the porosity showed larger effects in the Z-oriented specimen.

The fracture surfaces of the specimens at $650{ }^{\circ} \mathrm{C}$ are shown in Fig. 13, revealing transgranular fracture similar to those at $25{ }^{\circ} \mathrm{C}$ in Fig. 12. Facets formed via octahedral slip were commonly observed in Fig. 13a, d and g. Fatigue striations were observed in all specimens of three orientations in Fig. 13b, e and h, indicating similar plastic deformation assisted propagation. In the higher $\Delta \mathrm{K}$ regions, secondary cracks were evident in XZ650 specimen, which would be beneficial for crack branching and hence delay the propagation of primary crack. Remarkable porosity was noticed in Z650 specimen, similar to that of Z25. The microstructural anisotropy caused by build orientation is reasonable for the observed difference in fracture surfaces.

\subsection{Fatigue crack growth rate}

In this study, IN718 specimens in three different orientations were studied at both $25{ }^{\circ} \mathrm{C}$ and $650{ }^{\circ} \mathrm{C}$. The fatigue crack growth rate (FCGR) was evaluated for each sample, to reveal the effects of orientation and temperature. According to the ASTM guide, the number of loading cycles $N$ and the crack growth lengths $a$ were recorded during fatigue testing. The results were plotted in Fig. 14, which shows that fatigue crack length increases evidently with the number of cycles $N$. For the specimens at $25{ }^{\circ} \mathrm{C}$, the curves of X25, XZ25, and Z25 are close to each other. There is slight difference in the slope of curve especially at the later stage of propagation, following Z25 > X25 > XZ25, indicating that Z25 specimen showed the highest FCGR. For the specimens at $650{ }^{\circ} \mathrm{C}$ in Fig. 14, the curves are more separated than those at $25{ }^{\circ} \mathrm{C}$, partially due to the effect of orientation on fatigue crack initiation process. The specimen Z650 showed earlier onset of crack propagation and longer crack length than the other specimens. However, the difference in the curve slopes (i.e. FCGR) is not so evident between X650, XZ650, and Z650 specimens.

Further, the FCGR can be calculated by the slope $(d a / d N)$ of crack length increment per cycle, given by:

$(d a / d N)_{i}=\left(a_{i+1}-a_{i}\right) /\left(N_{i+1}-N_{i}\right)$

The stress intensity factor (SIF) range for a single edge notched plate of finite width is given by:

$\Delta K=\Delta \sigma \sqrt{\pi(a+b)} F(a / W)$

where $\Delta \sigma$ is the stress range, $b$ is the depth of notch, $a$ is the crack length defined as the projected length vertical to the loading axis, and $W$ is the width of specimen. Let $\xi=a / W$, the function of $F(\xi)(\xi=a / W)$ is defined as [16].

$F(\xi)=0.265(1-\xi)^{4}+(0.857+0.265 \xi)(1-\xi)^{-3 / 2}$

As adopted in many studies, the crack growth can be related to the 

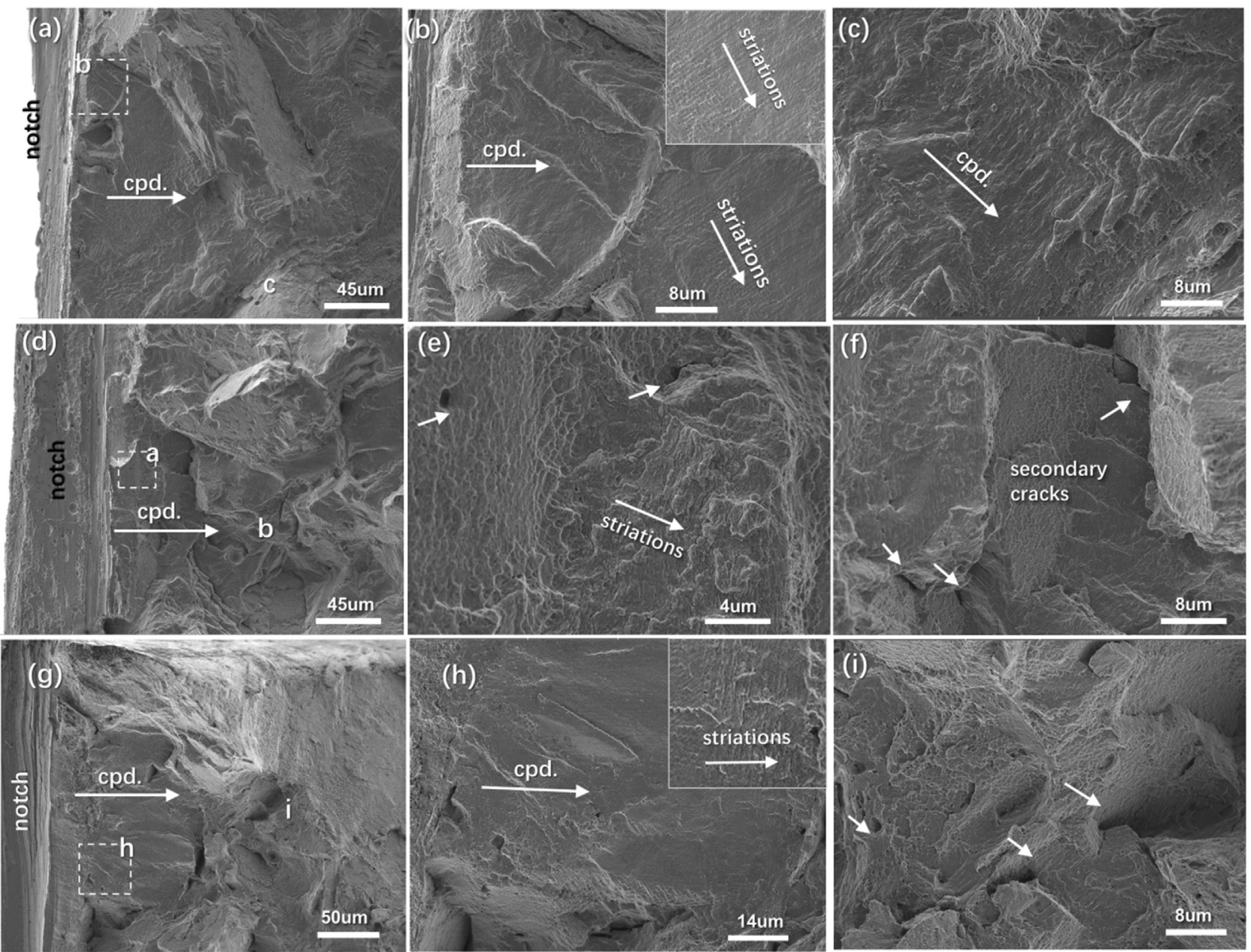

Fig. 13. Fatigue fracture surfaces observation of IN718 alloy showing the effects of orientation at $650^{\circ} \mathrm{C}$ : (a)-(c) X650 specimen; (d)-(f) XZ650 specimen; (g)-(i) Z650 specimen.



Fig. 14. Fatigue crack length versus the number of load cycles for IN718 alloy (X, XZ, and Z orientations) at $25^{\circ} \mathrm{C}$ and $650{ }^{\circ} \mathrm{C}$.

stress intensity range as first proposed by Paris and Erdogan [26]. Hence, the $\mathrm{da} / \mathrm{dN}$ versus $\Delta K$ curves of different specimens were examined in this study.

The fatigue crack growth rate curves of IN718 alloy in three different orientations are shown in Fig. 15(a) for $25^{\circ} \mathrm{C}$ and Fig. 15(b) for $650{ }^{\circ} \mathrm{C}$, respectively. The data points in Fig. 15 correspond to the fatigue specimens shown in Figs. 6-11. The data points for $\mathrm{X}, \mathrm{XZ}$, and $\mathrm{Z}$ direction specimen were marked as black, red, and blue points respectively. It is seen that at $25{ }^{\circ} \mathrm{C}$ the specimen in $\mathrm{Z}$ orientation showed the fastest FCGR above the others, and the one in XZ orientation showed the lowest FCGR, with the X-orientated specimen in between. The effect of orientation on FCGR is similar to the previous studies of long fatigue crack propagation [5]. The maximum stress intensity factor before final facture is smallest for the specimen in $\mathrm{Z}$ orientation, indicating the lowest fracture toughness accordingly. In Fig. 15b, the effect of orientation on FCGR at $650{ }^{\circ} \mathrm{C}$ also follows the same trend, that is, $\mathrm{XZ}>\mathrm{X}>\mathrm{Z}$, although the difference between the curves of $\mathrm{X}$ and $\mathrm{XZ}$ orientation was less pronounced than that of $25^{\circ} \mathrm{C}$. Furthermore, it is interesting to notice that the FCGR curves of all samples commonly showed evident fluctuations, which is distinct from the fatigue long crack growth behavior [10]. Also, the fracture toughness is smallest for the Z-orientated specimen at $650{ }^{\circ} \mathrm{C}$. Moreover, it is found that FCGR is remarkably affected by temperature, i.e. the FCGR at $650{ }^{\circ} \mathrm{C}$ for each orientation was almost an order of magnitude higher than that of $25^{\circ} \mathrm{C}$, which is similar to the results reported in wrought IN718 alloy [12].

\section{Discussion}

\subsection{Microstructure-sensitive short crack behavior}

It is known that fatigue short crack is more sensitive to local microstructures than that of long crack. According to previous studies on nickel-based superalloys $[14,15,17,27]$, the interaction between fatigue crack and microstructural inhomogeneity (e.g. grain boundary, twin 



Fig. 15. Fatigue crack growth rate $\mathrm{da} / \mathrm{dN}$ versus stress intensity range $\Delta \mathrm{K}$ curves of IN718 alloy (X, XZ, and Z orientations): (a) at room temperature, (b) at $650{ }^{\circ} \mathrm{C}$.

boundary, inclusion etc.) or secondary cracks has important role in the extension of fatigue crack. The short crack propagation of IN718 alloy by SLM showed evident fluctuation in all examined samples in Figs. 611. The crack path is entirely transgranular for crack growth ranging from the short crack region to the end of rapid rupture, which is consistent with previous studies on wrought IN718 [12,13]. Fig. 16 summarizes the effects of microstructure on the fatigue crack growth rate deceleration and acceleration for each of the six testing cases. For X25 specimen (X orientation, at $25{ }^{\circ} \mathrm{C}$ ), there are three evident drops in the FCGR curve (marked as 'A1', 'A2' and 'A3' in Fig. 16a), which is commonly related to the impeding effects of grain boundaries to fatigue crack extension. For XZ25 specimen (XZ orientation, at $25{ }^{\circ} \mathrm{C}$, see Fig. 16c), the FCGR curve appears more fluctuated, in which 'B1' and ' $\mathrm{B} 4$ ' are found to be associated with the retardation of grain boundary. ' $\mathrm{B} 2$ ' is related to the interaction of crack with grain boundary and slip bands. 'B3' is due to the constraint of fatigue crack tip in slip band while the inclined propagation direction is inefficient in extending the crack length. For Z25 specimen ( $\mathrm{Z}$ orientation, at $25{ }^{\circ} \mathrm{C}$, see Fig. $16 \mathrm{e}$ ), the retardation by grain boundary was less pronounced even though there were multiple grain boundaries ahead of crack tip, with ' $\mathrm{C} 1$ ' as an example that worked as barrier.

For the specimens at $650{ }^{\circ} \mathrm{C}$, the impeding effects of grain boundaries were similar to those of $25{ }^{\circ} \mathrm{C}$. It is evidently noticed in the specimen X650 (Fig. 16b) and XZ650 (Fig. 16d) that the cracks were arrested and branched at ' $\mathrm{J} 2$ ' and ' $\mathrm{J} 3$ '. Besides, there is usually a remarkable increase of crack opening displacement while being blocked, followed by accelerated fatigue crack growth, as shown in Fig. 16d and Fig. 16f. For crystallographic cracking observed in this study, it is generally believed that the adjacent grain orientations are important factors affecting the role of grain boundary while interacting with fatigue crack and persistent slip bands. Former studies [28-30] indicated that the larger misorientation between two neighboring grains, the more pronounced will be the deceleration of FCGR at grain boundary. Marx et al. [31] performed focused ion beam tomography study of fatigue short crack and suggested that there was a critical misorientation value for the crack to pass the grain boundary. McDowell et al. [29] developed 3D crystal plasticity modeling to evaluate the change of local driving force and the effects of grain orientation, grain boundary characters (twist/tilt, misorientation) on the extension of transgranular fatigue crack at early stage. The driving force of crack propagation cannot increase monotonically at the short crack regime, which lead to the fluctuation of FCGR related to local microstructures. Regarding the feature of microstructurally short crack, previous studies [15] indicate that carbide can also act as microstructural obstacle to crack propagation despite of crack initiator [32]. Some carbides were also observed in the fatigue crack paths, e.g. Fig. 7c and Fig. 16c, which however did not play such an important role as the grain boundary shown above.

Note that in this study, the short cracks did not propagate significantly faster than the long cracks as usually expected. The study of small crack behaviors in wrought IN718 alloy reported similar results [12]. Another difference in the SLM IN718 alloy is the presence of microstructural barriers, such as dense grain boundaries. They have been shown in Fig. 16 to slow progression of the crack, effectively blunting crack tip, or forming secondary cracks, and lead to evident delay in crack propagation. Secondly, the crack length is on the order of the plastic zone size, thus violating the small yielding condition of linear elastic fracture mechanics $[14,15,17]$, indicating mechanically small crack. The characterization of crack tip interaction with defects in SLM Ti6Al4V revealed that slower small FCGR can be attributed to both aforementioned effects [33]. Hence, the fatigue crack growth in SLM IN718 can be considered as small both microstructually and mechanically.

\subsection{Effect of temperature}

In contrast with the research of fatigue crack propagation at room temperature, in-situ study at high temperature was rather limited due to technical difficulties and experimental efforts. Previous studies $[13,34]$ on fatigue crack propagation behavior of conventional IN718 alloy reported a transition from transgranular to intergranular fracture at $650{ }^{\circ} \mathrm{C}$, due to oxidation assisted grain boundary cracking. The fatigue short crack showed similar fracture behavior according to the studies of IN718 alloy by Zhang et al. [12]. However, in the present study, fatigue cracks favored propagation via the occurrence of crystallographic slip, leading to solely transgranular fracture in all samples regardless of orientation or temperature. Note that all fatigue tests were performed in the SEM chamber, i.e. vacuum condition, Hence, it is consistent with Cornnolley's studies [13] on wrought IN718 alloy that transgranular cracking was dominant in vacuum, when oxidation effects were excluded. Fatigue cracks in Figs. 6-11 are known to be octahedral crystallographic cracking, i.e. along $\left\{\begin{array}{lll}1 & 1 & 1\end{array}\right\}$ planes, which are the preferred crack propagation manner at low temperatures and high frequencies in Ni-based superalloys [15]. Furthermore, fatigue crack propagation at $650{ }^{\circ} \mathrm{C}$ was less tortuous compared to that of $25{ }^{\circ} \mathrm{C}$, in accordance with the increased FCGR due to the propensity of multiple slips and less pronounced impeding effects of grain boundaries, which was also reported in similar superalloys [15].

By comparing the fatigue crack growth curves at both temperatures in Fig. 16, it is obvious that the FCGR is much higher at $650{ }^{\circ} \mathrm{C}$ than that of $25^{\circ} \mathrm{C}$, for either $\mathrm{X}, \mathrm{XZ}$, or $\mathrm{Z}$ orientation. Note that a maximal stress of 



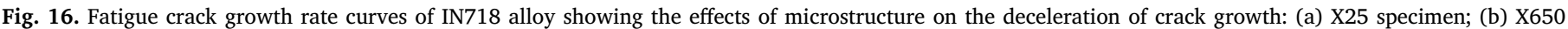
specimen; (c) XZ25 specimen; (d) XZ650 specimen; (e) Z25 specimen; (f) Z650 specimen.

$890 \mathrm{MPa}$ for $25^{\circ} \mathrm{C}$ and $735 \mathrm{MPa}$ for $650{ }^{\circ} \mathrm{C}$ was adopted in the fatigue testing, to make the total deformation of specimen comparable at each temperature. The reduced fatigue crack growth resistance at high temperature can be generally attributed to strength decrease $[12,15,35]$, cyclic softening, and oxidation-induced degradation etc [12]. Shyam [35] reported that the fatigue crack growth rate at $20{ }^{\circ} \mathrm{C}$, $150{ }^{\circ} \mathrm{C}$ and $250{ }^{\circ} \mathrm{C}$ can be consolidated by the plastic zone size, incorporating the decreasing yield strength with temperature. In the case of IN718 alloy by SLM, the knowledge on the temperature dependence of mechanical properties is limited and the influence on tensile properties is likely to be similar to that of the conventional IN718 alloy [6]. For wrought IN718 alloy, it is reported that there is about $20 \%$ to $33 \%$ drop in yield stress when the temperature increases from $25{ }^{\circ} \mathrm{C}$ to $650{ }^{\circ} \mathrm{C}$ [12]. Regarding the oxidation effects, considering that the present fatigue testing is in vacuum, it has excluded the effects of oxidation-induced embrittlement. Hence, in the present study the higher FCGR at $650{ }^{\circ} \mathrm{C}$ is primarily attributed to the reduction of material strength. 


\subsection{Influence of specimen orientation}

It is known that alloys fabricated by SLM show anisotropy in mechanical properties due to different microstructures along the building direction (Z) and the scanning orientation (X). As shown in Fig. 4, distinct microstructures were observed on the top surfaces of the specimens along $\mathrm{X}, \mathrm{Z}$, and $\mathrm{XZ}$ orientations. One of the primary differences in microstructure, e.g. grain boundaries, was shown to evidently affect the interaction of fatigue crack with local barriers, causing temporary arrest and subsequent acceleration of FCGR as shown in Fig. 16.

According to the EBSD result in Fig. 5, for the Z-oriented specimens, the adjacent grains had much smaller misorientation than those of $\mathrm{X}$ and XZ oriented specimens, which provides less resistance to fatigue crack propagation according to the studies of McDowell and Zhang et al. [29-31]. Additionally, the X-oriented specimens have more small equiaxed grains as shown in the X-Y plane of Fig. 5, which is more beneficial to fatigue crack growth resistance due to more grain boundaries encountered during crack propagation. Hu et al. [10] also reported similar effects on the fatigue long crack growth of Inconel 625 alloy. For the XZ-oriented specimen, it is similar to that of X-oriented specimen and moreover, the loading axis was $45^{\circ}$ inclined off the buildup direction and the longitudinal grain boundaries, which is believed to increase the tortuosity of crack path and the fluctuation in FCGR for XZ specimen, as shown in Fig. 7 and Fig. 10.

Additionally, Qian et al. [36] reported lower FCGR in X orientation than that of $\mathrm{Z}$ orientation in titanium alloy fabricated by SLM, which was attributed to higher porosity on the layers perpendicular to the $\mathrm{Z}$ direction and more secondary cracks in the X-oriented specimen. It is also observed in this study (in Figs. 8 and 11) that the FCG path is less tortuous, associated with less secondary cracks, in the Z-oriented specimens compared with those in $\mathrm{X}$ and $\mathrm{XZ}$ orientations. For the microvoid commonly formed during SLM process, which has been reported to greatly influence fatigue crack initiation in smooth specimens, its effect on fatigue crack growth was not so evident in this study. It is partly due to the small size of microvoids in the present IN718 alloy (maximum frequency of $5 \mu \mathrm{m}$ and average size of $9 \mu \mathrm{m}$ indicated by 3D-XRT imaging) rarely observed on the specimen surface and the high stress intensity at the crack tip, which is consistent with the study of SLM Inconel 625 alloy by Hu et al. [10].

The above anisotropic microstructure also leads to evident difference in mechanical properties, e.g. the yield stress and tensile strength. In the present study, additional tensile tests of SLM IN718 alloy indicated that the yield stress along the $\mathrm{Z}$ direction is about $80 \%$ of that along the $\mathrm{X}$ direction. It is also reported in SLM IN718 alloy $[1,11]$ and IN625 alloy [10] that lower yield stress was noticed in $\mathrm{Z}$ direction than that of $\mathrm{X}$ direction, even after solution heat treatment. The strength difference was responsible for the larger effective crack driving force as a function of crack tip plastic zone size in Z direction [10]. Previous studies [35] suggest that the small fatigue crack growth was affected by both the accumulated irreversible cyclic plastic damage at crack tip and the tensile plastic deformation at crack-tip to cause local fracture and crack extension. Shyam et al. [35] proposed a small crack growth model by taking the product of the cyclic crack-tip opening displacement, $\phi_{c}$, and the monotonic crack-tip opening displacement, $\phi_{m}$, as the crack driving force, based on the dislocation density field theory of Bilby, Cottrell and Swinden [37]. The two parameters, $\phi_{c}$ and $\phi_{m}$, are function of the yield stress $\sigma_{y s}$, the maximal stress $\sigma_{\max }$ during a full cycle, and the Young's modulus, $E$. The parameter $\phi_{c} \phi_{m}$ decreases with higher yield stress, leading to smaller FCGR, which was reported to be able to correlate the FCGR curves of varying strength materials under different temperatures [35]. Zhang et al. [12] also suggested that Shyam's model was likely to characterize the small FCGR of IN718 alloys with varying grain size to some extent. This model can be also used to explain the higher FCGR along the $\mathrm{Z}$ orientation, compared to that of $\mathrm{X}$ and $\mathrm{XZ}$ orientations. Nevertheless, the short fatigue crack growth can be affected by several factors, for instance, the crystallographic slip manner at different temperatures [15], interaction between fatigue short cracks and slip bands [14], adjacent cracks, and grain boundaries [14]. Especially, the impeding effects of grain boundaries were evidently observed in the present work, which usually led to an increase of crack tip opening displacement when the crack was retarded at a grain boundary. At this moment, the fatigue crack growth would decelerate, corresponding to a large CTOD. This deviation would make the models based on CTOD somehow difficult to deal with microstructurally small crack growth. Quantitative studies on the driving force of fatigue short crack based on high resolution in-situ characterizations of CTOD and cyclic plastic zone are needed to add more lights to this issue in future work.

\section{Conclusions}

The effects of orientation and temperature on the fatigue short crack growth behavior of Inconel 718 alloy fabricated by selected laser melting was studied by in situ SEM fatigue testing. The following conclusions have been obtained in this work:

(1) Fatigue crack initiation occurred at the notch root following crystallographic way associated with octahedral slip deformation, regardless of specimen orientations under both testing temperatures in this study. The subsequent crack propagation exhibited commonly transgranular fracture mode for all specimens.

(2) Fatigue crack growth rates showed remarkable fluctuations for all testing cases. The deceleration was closely related to the blocking effects of grain boundaries formed by selective laser melting, and a subsequent acceleration was found after exceeding the microstructural barriers or coalescence with adjacent cracks.

(3) The fatigue short crack growth rates of Inconel 718 alloy showed evident orientation dependence. Fatigue cracks propagated much faster in the $\mathrm{Z}$ orientation specimen than that of the other two orientations (X and $\mathrm{XZ}$ ), mostly due to the small misorientation of adjacent grains of Zoriented specimen following a cube texture and the lower strength along the build-up orientation ( $\mathrm{Z}$ orientation). XZ-specimen showed slighter lower FCGR than that of $\mathrm{X}$ specimen under room temperature, which became less distinguishable under $650{ }^{\circ} \mathrm{C}$.

(4) The fatigue short crack growth rates at $650{ }^{\circ} \mathrm{C}$ were higher than those at $25^{\circ} \mathrm{C}$, which can be attributed to reduced material strength and less blocking effects of grain boundary at elevated temperature, in accordance with less tortuous fatigue crack path at $650{ }^{\circ} \mathrm{C}$.

\section{Declaration of Competing Interest}

The authors declare that they have no known competing financial interests or personal relationships that could have appeared to influence the work reported in this paper.

\section{Acknowledgements}

This project is supported by the National Science Foundation of China (No. 11902370, 11932020, 11872364), Guangdong Major Project of Basic and Applied Basic Research (2019B030302011), International Sci \& Tech Cooperation Program of GuangDong Province (2019A050510022), Key-Area Research and Development Program of GuangDong Province (2019B010943001), Guangdong Education Department Fund (2016KQNCX005), China Postdoctoral Science Foundation (2019M653173 and 2019TQ0374), and Fundamental Research Funds for the Central Universities (19lgpy304). Guian Qian acknowledges the support by CAS Pioneer Hundred Talents Program.

\section{References}

[1] Hosseini E, Popovich VA. A review of mechanical properties of additively manufactured Inconel 718. Addit Manuf 2019;30:100877.

[2] Trosch T, et al. Microstructure and mechanical properties of selective laser melted 
Inconel 718 compared to forging and casting. Mater Lett 2016;164:428-31.

[3] Smith DH, et al. Microstructure and mechanical behavior of direct metal laser sintered Inconel alloy 718. Mater Charact 2016;113:1-9.

[4] Gribbin S, et al. Low cycle fatigue behavior of direct metal laser sintered Inconel alloy 718. Int J Fatigue 2016;93:156-67.

[5] Konečná R, et al. Long fatigue crack growth in Inconel 718 produced by selective laser melting. Int J Fatigue 2016;92:499-506.

[6] Wan HY, et al. Effect of scanning strategy on mechanical properties of selective laser melted Inconel 718. Mater Sci Eng, A 2019;753:42-8.

[7] Zhang D, et al. Effect of standard heat treatment on the microstructure and mechanical properties of selective laser melting manufactured Inconel 718 superalloy. Mater Sci Eng, A 2015;644:32-40.

[8] Deng D, et al. Microstructure and anisotropic mechanical properties of EBM manufactured Inconel 718 and effects of post heat treatments. Mater Sci Eng, A 2017;693:151-63.

[9] Watring DS, et al. Mechanisms driving high-cycle fatigue life of as-built Inconel 718 processed by laser powder bed fusion. Materials Science and Engineering aStructural Materials Properties Microstructure and Processing. 2019. p. 761.

[10] Hu XA, et al. On the fatigue crack growth behaviour of selective laser melting fabricated Inconel 625: Effects of build orientation and stress ratio. Fatigue Fract Eng Mater Struct 2020;43(4):771-87.

[11] Chern AH, et al. A review on the fatigue behavior of Ti-6Al-4V fabricated by electron beam melting additive manufacturing. Int J Fatigue 2019;119:173-84.

[12] Zhu X, et al. Influence of grain size on the small fatigue crack initiation and propagation behaviors of a nickel-based superalloy at $650^{\circ} \mathrm{C}$. J Mater Sci Technol 2019;35(8):1607-17.

[13] Connolley T, Reed PAS, Starink MJ. Short crack initiation and growth at $600^{\circ} \mathrm{C}$ in notched specimens of Inconel718. Mater Sci Eng, A 2003;340(1):139-54.

[14] Ma X, Shi HJ. In situ SEM studies of the low cycle fatigue behavior of DZ4 superalloy at elevated temperature: Effect of partial recrystallization. Int J Fatigue 2014;61:255-63.

[15] Ma XF, Shi HJ. On the fatigue small crack behaviors of directionally solidified superalloy DZ4 by in situ SEM observations. Int J Fatigue 2012;35(1):91-8.

[16] Wang XS, Fan JH. An evaluation on the growth rate of small fatigue cracks in cast AM50 magnesium alloy at different temperatures in vacuum conditions. Int J Fatigue 2006;28(1):79-86.

[17] Ma XF, et al. In-situ observations of the effects of orientation and carbide on low cycle fatigue crack propagation in a single crystal superalloy. Procedia Eng 2010;2(1):2287-95.

[18] Jiang R, et al. Characterisation of strain localisation processes during fatigue crack initiation and early crack propagation by SEM-DIC in an advanced disc alloy. Mater Sci Eng, A 2017;699:128-44.

[19] Lia WP, et al. Fracture mechanisms of a Mo alloyed CoCrFeNi high entropy alloy: Insitu SEM investigation. Mater Sci Eng, A 2018;723:79-88.
[20] Han Q-N, et al. The effect of crystal orientation on fretting fatigue crack formation in Ni-based single-crystal superalloys: In-situ SEM observation and crystal plasticity finite element simulation. Tribol Int 2018.

[21] Wan HY, et al. Effect of scanning strategy on grain structure and crystallographic texture of Inconel 718 processed by selective laser melting. J Mater Sci Technol 2018;34(10):1799-804.

[22] Wang Z, et al. The microstructure and mechanical properties of deposited-IN718 by selective laser melting. J Alloy Compd 2012;513:518-23.

[23] Jinhui L, et al. Study on formation of surface and microstructure of stainless stee part produced by selective laser melting. Mater Sci Technol 2010;26(10):1259-64.

[24] Yadroitsev I, et al. Strategy of manufacturing components with designed internal structure by selective laser melting of metallic powder. Appl Surf Sci 2007;254(4):980-3.

[25] Thijs L, et al. Strong morphological and crystallographic texture and resulting yield strength anisotropy in selective laser melted tantalum. Acta Mater 2013;61(12):4657-68.

[26] Paris P, Erdogan F. A critical analysis of crack propagation laws. 1963.

[27] Qiu WH, et al. Effects of secondary orientation on crack closure behavior of nickelbased single crystal superalloys. Int J Fatigue 2016;83:335-43.

[28] Gribbin S, et al. Role of grain structure, grain boundaries, crystallographic texture, precipitates, and porosity on fatigue behavior of Inconel 718 at room and elevated temperatures. Mater Charact 2019;149:184-97.

[29] Castelluccio GM, Musinski WD, McDowell DL. Recent developments in assessing microstructure-sensitive early stage fatigue of polycrystals. Curr Opin Solid State Mater Sci 2014;18(4):180-7.

[30] Zhang YH, Edwards L. On the blocking effect of grain boundaries on small crystallographic fatigue crack growth. Mater Sci Eng, A 1994;188(1):121-32.

[31] Schäf W, Marx M, Knorr AF. Influence of microstructural barriers on small fatigue crack growth in mild steel. Int J Fatigue 2013;57:86-92.

[32] Huang X, et al. Experimental investigation on microcrack initiation process in nickel-based superalloy DAGH4169. Int J Fatigue 2012;42:153-64.

[33] Waddell M, et al. Small fatigue crack growth behavior of Ti-6Al-4V produced via selective laser melting: In situ characterization of a 3D crack tip interactions with defects. Int J Fatigue 2020;137:105638.

[34] Mercer C, Soboyejo ABO, Soboyejo WO. Micromechanisms of fatigue crack growth in a forged Inconel 718 nickel-based superalloy. Mater Sci Eng, A 1999;270(2):308-22.

[35] Shyam A, et al. Small fatigue crack growth in metallic materials: A model and its application to engineering alloys. Acta Mater 2007;55(19):6606-16.

[36] Qian G, et al. In-situ investigation on fatigue behaviors of Ti-6Al-4V manufactured by selective laser melting. Int J Fatigue 2020;133.

[37] Bilby BA, Cottrell AH, Swinden KH. The spread of plastic yield from a notch. Proceedings of the Royal Society A, 1963. 272(1350): p. 304-14. 